\title{
Flame Radiation, Structure, and Scalar Properties in Microgravity Laminar Fires
}

Douglas Feikema

Glenn Research Center, Cleveland, Ohio

Jongmook Lim and Yudaya Sivathanu

En'Urga, Inc., West Lafayette, Indiana 


\section{NASA STI Program . . . in Profile}

Since its founding, NASA has been dedicated to the advancement of aeronautics and space science. The NASA Scientific and Technical Information (STI) program plays a key part in helping NASA maintain this important role.

The NASA STI Program operates under the auspices of the Agency Chief Information Officer. It collects, organizes, provides for archiving, and disseminates NASA's STI. The NASA STI program provides access to the NASA Aeronautics and Space Database and its public interface, the NASA Technical Reports Server, thus providing one of the largest collections of aeronautical and space science STI in the world. Results are published in both non-NASA channels and by NASA in the NASA STI Report Series, which includes the following report types:

- TECHNICAL PUBLICATION. Reports of completed research or a major significant phase of research that present the results of NASA programs and include extensive data or theoretical analysis. Includes compilations of significant scientific and technical data and information deemed to be of continuing reference value. NASA counterpart of peer-reviewed formal professional papers but has less stringent limitations on manuscript length and extent of graphic presentations.

- TECHNICAL MEMORANDUM. Scientific and technical findings that are preliminary or of specialized interest, e.g., quick release reports, working papers, and bibliographies that contain minimal annotation. Does not contain extensive analysis.

- CONTRACTOR REPORT. Scientific and technical findings by NASA-sponsored contractors and grantees.
- CONFERENCE PUBLICATION. Collected papers from scientific and technical conferences, symposia, seminars, or other meetings sponsored or cosponsored by NASA.

- SPECIAL PUBLICATION. Scientific, technical, or historical information from NASA programs, projects, and missions, often concerned with subjects having substantial public interest.

- TECHNICAL TRANSLATION. Englishlanguage translations of foreign scientific and technical material pertinent to NASA's mission.

Specialized services also include creating custom thesauri, building customized databases, organizing and publishing research results.

For more information about the NASA STI program, see the following:

- Access the NASA STI program home page at http://www.sti.nasa.gov

- E-mail your question via the Internet to help@sti.nasa.gov

- Fax your question to the NASA STI Help Desk at 301-621-0134

- Telephone the NASA STI Help Desk at 301-621-0390

- Write to: NASA Center for AeroSpace Information (CASI) 7115 Standard Drive Hanover, MD 21076-1320 
NASA/TM-2007-214683

AIAA-2007-0734

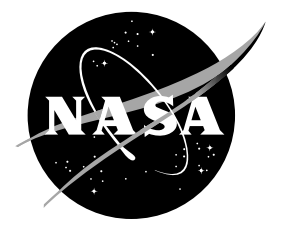

\section{Flame Radiation, Structure, and Scalar Properties in Microgravity Laminar Fires}

Douglas Feikema

Glenn Research Center, Cleveland, Ohio

Jongmook Lim and Yudaya Sivathanu

En'Urga, Inc., West Lafayette, Indiana

Prepared for the

45th Aerospace Sciences Meeting and Exhibit

sponsored by the American Institute of Aeronautics and Astronautics

Reno, Nevada, January 8-11, 2007

National Aeronautics and

Space Administration

Glenn Research Center

Cleveland, Ohio 44135 


\section{Acknowledgments}

This work is supported by NASA under contract no. NAS3-01085 by the Microgravity Combustion Program, from 2000 to 2004. The authors also acknowledge the support of Jason Taylor and Brian Clark who completed the drop tests and data reduction. The drop tower support personnel are also gratefully acknowledged.

This report is a formal draft or working paper, intended to solicit comments and ideas from a technical peer group.

This report contains preliminary findings, subject to revision as analysis proceeds.

Trade names and trademarks are used in this report for identification only. Their usage does not constitute an official endorsement, either expressed or implied, by the National Aeronautics and Space Administration.

Level of Review: This material has been technically reviewed by technical management.

Available from

NASA Center for Aerospace Information 7115 Standard Drive

Hanover, MD 21076-1320
National Technical Information Service 5285 Port Royal Road Springfield, VA 22161 


\title{
Flame Radiation, Structure, and Scalar Properties in Microgravity Laminar Fires
}

\author{
Douglas Feikema \\ National Aeronautics and Space Administration \\ Glenn Research Center \\ Cleveland, Ohio 44135 \\ Jongmook Lim and Yudaya Sivathanu \\ En'Urga, Inc. \\ West Lafayette, Indiana 47906
}

\begin{abstract}
Results from microgravity combustion experiments conducted in the Zero Gravity Research Facility (ZGF) 5.18 second drop facility are reported. The results quantify flame radiation, structure, and scalar properties during the early phase of a microgravity fire. Emission mid-infrared spectroscopy measurements have been completed to quantitatively determine the flame temperature, water and carbon dioxide vapor concentrations, radiative emissive power, and soot concentrations in microgravity laminar methane/air, ethylene/nitrogen/air and ethylene/air jet flames. The measured peak mole fractions for water vapor and carbon dioxide are found to be in agreement with state relationship predictions for hydrocarbon/air combustion. The ethylene/air laminar flame conditions are similar to previously reported results including those from the flight project, Laminar Soot Processes (LSP). Soot concentrations and gas temperatures are in reasonable agreement with similar results available in the literature. However, soot concentrations and flame structure dramatically change in long-duration microgravity laminar diffusion flames as demonstrated in this report.
\end{abstract}

\section{Introduction}

The present study of microgravity laminar diffusion flames was motivated by a requirement for improved understanding of fires in manned spacecraft. NASA's fire safety approach for manned spacecraft has been based primarily upon controlling the flammability of materials onboard and eliminating ignition sources (refs. 1 to 3). To develop effective fire protection systems, the behavior of fires in various environments encountered in space exploration must be properly understood. Fire behavior and suppression processes in the space exploration missions are strongly influenced by lowgravity environments in flight and on the planetary surfaces. Thus, fire safety technology must be tailored to respond to the unusual fire characteristics in low-gravity environments (ref. 1). The nonbuoyant microgravity environment causes substantial changes in flame structure and consequently changes the properties of the produced smoke and/or soot. In particular, the increased residence time in the high temperature zone where the smoke and/or soot is formed, increases the probability that the particulate will become larger and agglomerated. Among the many technical issues to be answered, this report addresses the issue of flame structure in a simple laminar fire including chemical composition and soot production. Thermal radiation from soot contributes to the growth and spread of unwanted fires on Earth, and sootcontaining plumes emitted from these flames inhibit fire-fighting efforts on Earth. No less problematic are the carbon monoxide and unburned hydrocarbon emissions that intrinsically are associated with soot; carbon monoxide emissions are the main cause of fatalities in unwanted fires on Earth. In quiescent microgravity $(\mu \mathrm{g})$ environments, fires or diffusion flames are relatively weak because of the lack of buoyantly driven convective flow and the slower resulting diffusional transport. The flame on a thick sheet or rod tends to self-extinguish under quiescent conditions (refs. 4 to 6). However, there is normally a constant air circulation, typically $20 \mathrm{~cm} / \mathrm{s}$, inside the crew cabin which makes the microgravity flame stronger since oxygen is transported to the fire by forced convection. The flame spread rate in microgravity generally increases when the oxidizer flow velocity increases. 
Laminar hydrocarbon diffusion flames under microgravity conditions have shown distinct characteristics relative to normal-gravity flames. Flames are up to two times longer and up to four times larger in diameter, and are often more sooting in microgravity. These characteristics arise from the result of a significant reduction in buoyant convective forces which makes diffusion a dominant mechanism of transport. As a result, increased residence time, enhanced soot formation, radiative cooling due to larger flame size, and the possible onset of a chemical kinetics limitation on heat release processes are observed (ref. 7).

\section{Specific Objectives}

The objectives of this study are to examine scalar, radiative, and chemical properties of a wellcharacterized laminar fire (ref. 9) in short duration microgravity. The detailed results help quantify the structure of a nonbuoyant laminar fire which is significant since

fire safety technology must be tailored to respond to the unusual fire characteristics in low-gravity environments (ref. 8). In addition, methane/air and ethylene/nitrogen/air laminar jet flame case studies are reported for comparison and validation.

\section{Experimental Methods and Instrumentation}

The experiment consisted of a general purpose drop rig which was configured with a gas feed system and a laminar jet flame burning inside a chamber similar to the LSP flame (ref. 9). The experiment package was dropped in the Zero Gravity Facility (ZGF) 5.18 second drop facility. The flame conditions are presented in table I for a jet exit diameter of $1.65 \mathrm{~mm}$. Seven test cases are discussed and presented in this report for nearly identical flame conditions. A scanning mid-IR spectrometer, Spectraline Model No. ES100 (En'Urga Inc., West Lafayette, IN) (refs. 10 and 11), was used to obtain spectrally resolved radiation measurements which enabled quantitative determination of gas temperature, $\mathrm{CO}_{2}$ and $\mathrm{H}_{2} \mathrm{O}$ concentrations, and soot volume fraction. Other instrumentation included a radiometer (i.e., thermopile

TABLE I.-SUMMARY OF TEST CONDITIONS FOR MICROGRAVITY LAMINAR JET FLAMES

\begin{tabular}{|c|c|c|c|c|c|c|c|}
\hline \multicolumn{8}{|c|}{ Test number in Zero Gravity Research Facility } \\
\hline Conditions & $\mathrm{X}-12-5$ & $\mathrm{X}-12-6$ & $\mathrm{X}-12-18$ & $\mathrm{X}-12-19$ & $\mathrm{X}-12-16$ & $\mathrm{X}-12-17$ & $\mathrm{X}-7-5$ \\
\hline Fuel type & $\mathrm{CH}_{4}$ & $\mathrm{CH}_{4}$ & $\begin{array}{c}50 \% \mathrm{C}_{2} \mathrm{H}_{4} \\
50 \% \mathrm{~N}_{2}\end{array}$ & $\begin{array}{c}50 \% \mathrm{C}_{2} \mathrm{H}_{4} \\
50 \% \mathrm{~N}_{2}\end{array}$ & $\mathrm{C}_{2} \mathrm{H}_{4}$ & $\mathrm{C}_{2} \mathrm{H}_{4}$ & $\mathrm{C}_{2} \mathrm{H}_{4}$ \\
\hline Test pressure, $\mathrm{kPa}$ & 100 & 100 & 100 & 100 & 100 & 100 & 100 \\
\hline Test temperature, $\mathrm{K}$ & 300 & 300 & 300 & 300 & 300 & 300 & 300 \\
\hline $\begin{array}{l}\text { Average burner exit } \\
\text { velocity, } \mathrm{mm} / \mathrm{s}\end{array}$ & 1075 & 1075 & 935 & 935 & 935 & 935 & 935 \\
\hline $\begin{array}{l}\text { Initial chamber } \\
\text { oxygen } \\
\text { concentration, vol } \%\end{array}$ & 21 & 21 & 21 & 21 & 21 & 21 & 20.6 \\
\hline $\begin{array}{l}\text { Luminous flame } \\
\text { length, mm }\end{array}$ & 45 & 45 & 32 & 32 & 56 & 55 & 48 \\
\hline $\begin{array}{l}\text { Maximum luminous } \\
\text { flame width, mm }\end{array}$ & 32 & 32 & 14 & 14 & 25 & 25 & 26 \\
\hline Fuel flow rate, $\mathrm{mg} / \mathrm{s}$ & 1.49 & 1.49 & 2.3 & 2.3 & 2.3 & 2.3 & 2.3 \\
\hline Test duration, $\mathrm{s}$ & 5.08 & 5.08 & 5.08 & 5.08 & 5.08 & 5.08 & 5.08 \\
\hline $\begin{array}{l}\text { Characteristic flame } \\
\text { residence time, ms }\end{array}$ & 84 & 84 & 68 & 68 & 120 & 120 & 120 \\
\hline $\begin{array}{l}\text { Fuel exit Reynolds } \\
\text { number }\end{array}$ & 86 & 86 & 117 & 117 & 170 & 170 & 170 \\
\hline Purpose of test & $\begin{array}{l}\text { Spectrometer } \\
\text { scan at } \\
x / d^{\mathrm{a}}=13.6\end{array}$ & $\begin{array}{l}\text { Spectrometer } \\
\text { scan at } \\
x / d=17.6\end{array}$ & $\begin{array}{l}\text { Spectrometer } \\
\text { scan at } \\
x / d=17.6\end{array}$ & $\begin{array}{l}\text { Spectrometer } \\
\text { scan at } \\
x / d=12.0\end{array}$ & $\begin{array}{l}\text { Spectrometer } \\
\text { scan at } \\
x / d=13.6\end{array}$ & $\begin{array}{l}\text { Spectrometer } \\
\text { scan at } \\
x / d=17.6\end{array}$ & $\begin{array}{l}\text { Thermocouple } \\
\text { at } \\
x / d=12.0\end{array}$ \\
\hline
\end{tabular}

${ }^{\mathrm{a}}$ Here $x$ is the axial distance measured from the fuel tube exit and $d$ is the fuel tube exit diameter, $1.65 \mathrm{~mm}$. 
detector), R-type thermocouple rake, top and side views from the video camera sampling at $30 \mathrm{~Hz}$, and flow and pressure transducers. The flames are ignited in microgravity with a retractable hot-wire igniter approximately $0.1 \mathrm{~s}$ after the package is released. By igniting in microgravity, buoyant flow is eliminated enabling the flame to evolve in a quiescent environment.

Figure 1 shows a color side view and black and white top view of the methane/air flame after $5 \mathrm{~s}$ into the drop. The flame is "blue" without a glowing "yellow" soot continuum radiation region. The flame becomes less visible as microgravity duration increases, and after $2 \mathrm{~s}$ achieves near constant flame length and shape. The flame has an open tip end as seen in figure 1(b) and is nearly symmetric with a maximum visible flame length of $45 \mathrm{~mm}$. Figure 2 shows a color side view and black and white top view of the diluted 50 percent ethylene $/ 50$ percent nitrogen/air flame after $5 \mathrm{~s}$ into the drop. The flame is "blue" with glowing "yellow" soot continuum radiation region. The flame has a closed tip end as seen in figure 2(b) and is nearly symmetric. Figure 3 shows a color side view and black and white top view of an ethylene/air flame after $5 \mathrm{~s}$ into the drop. The flame is "blue" with glowing "yellow" soot continuum radiation region. The flame has an open tip end as seen in figure 3(b) and is nearly symmetric.

The flame length measurements shown in figure 4(a) have been taken from the side view color video camera for the diluted ethylene/nitrogen/air flame shown in figure 2(a). Initially, the flame is short at ignition and grows to attain a flame length of $32 \mathrm{~mm}$ on centerline after $5.0 \mathrm{~s}$. In normal gravity under buoyant conditions the same flame is $38 \mathrm{~mm}$ in length (ref. 9). The flame length measurements shown in figure 4(b) have been taken from the side view color video camera for the ethylene/air flame shown in figure 3(a). Initially, the flame is short at ignition and grows to attain a flame length of $55 \mathrm{~mm}$ on centerline after $5.0 \mathrm{~s}$, which is very similar to results obtained on the $\mathrm{KC}-135$ parabolic aircraft. In normal gravity under buoyant conditions, the same flame is $38 \mathrm{~mm}$ in length (ref. 9). Under longer duration microgravity conditions (i.e., $170 \mathrm{~s}$ ) the same flame increases in length to approximately $62 \mathrm{~mm}$ in length and reduces in width from $25 \mathrm{~mm}$ to $14 \mathrm{~mm}$ (ref. 9). Even after $5.0 \mathrm{~s}$ the flame is still not at steady state.
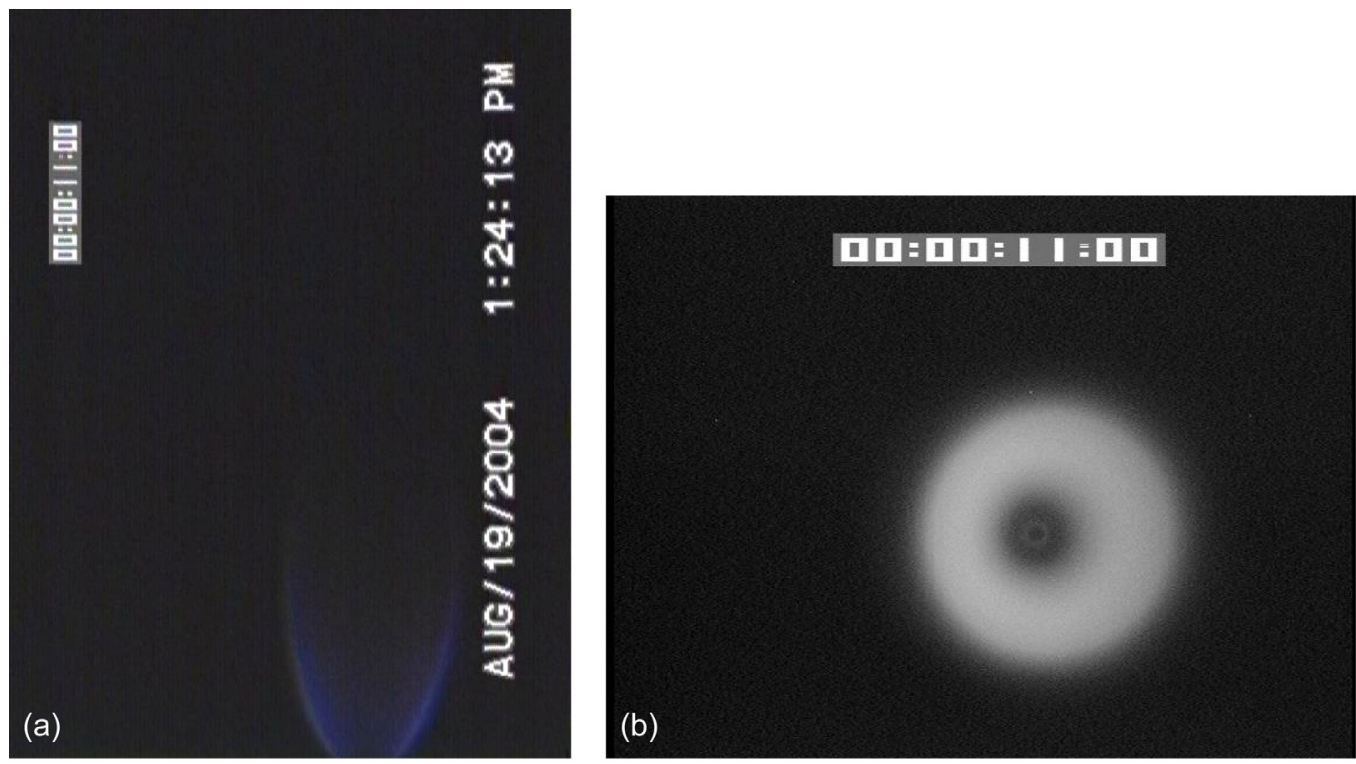

Figure 1.-(a) Side view color video camera still after 5.0 seconds for drop number $\mathrm{X}-12-6$, methane/air flame. (b) Top view blacklwhite video still after 5.0 seconds for same flame in figure 1(a) showing open tip. 

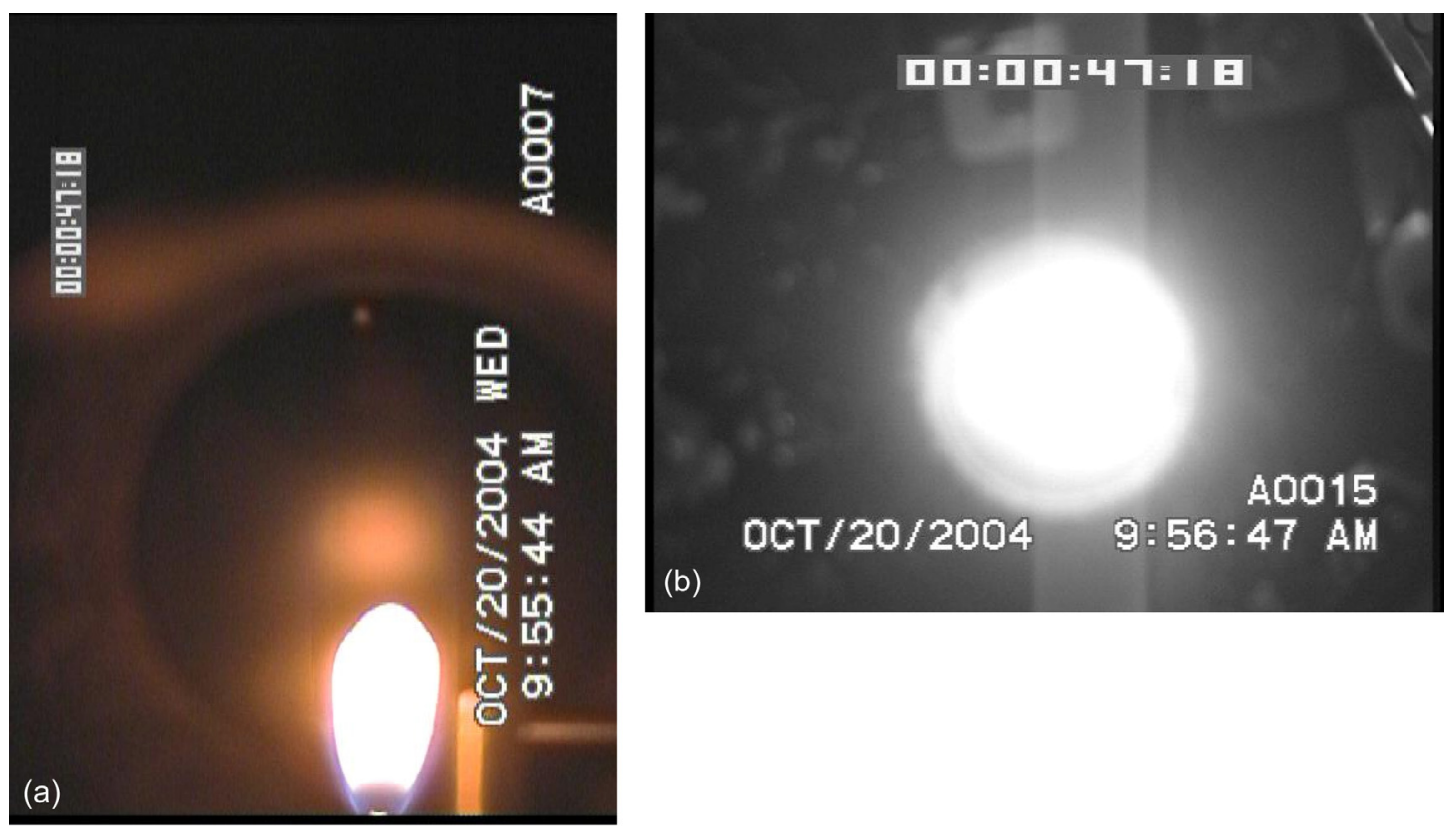

Figure 2.-(a) Side view color video camera still after 5.0 seconds for drop number $X-12-19,50 \%$ Ethylene and $50 \%$ nitrogen/air flame. (b)Top view blacklwhite video still after 5.0 seconds for same flame in figure 2(a) showing closed tip.
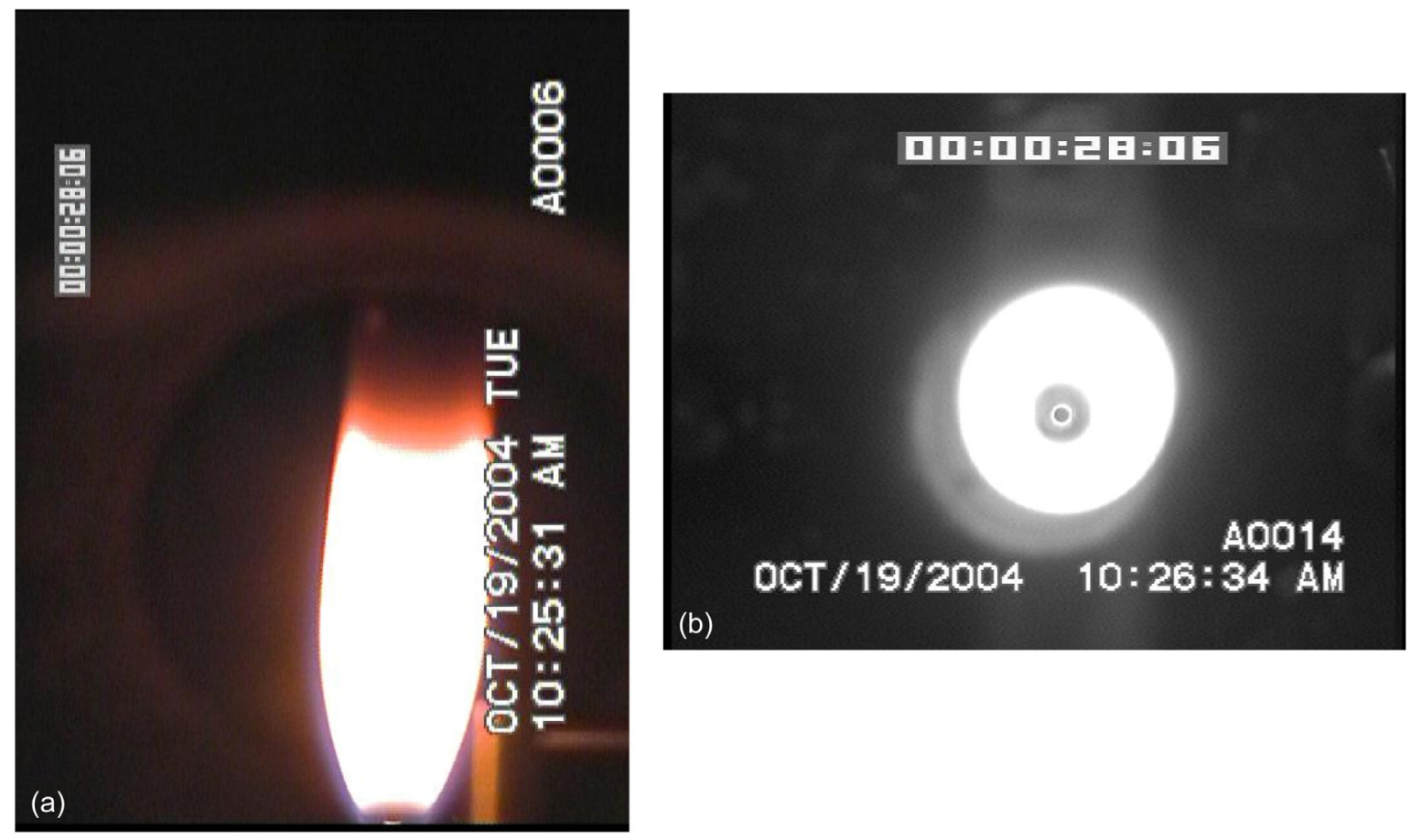

Figure 3.-(a) Side view color video camera still after 5.0 seconds for drop number $\mathrm{X}-12-17$, ethylene/air flame. (b) Top view blacklwhite video still after 5.0 seconds for same flame in figure 3(a) showing open tip. 

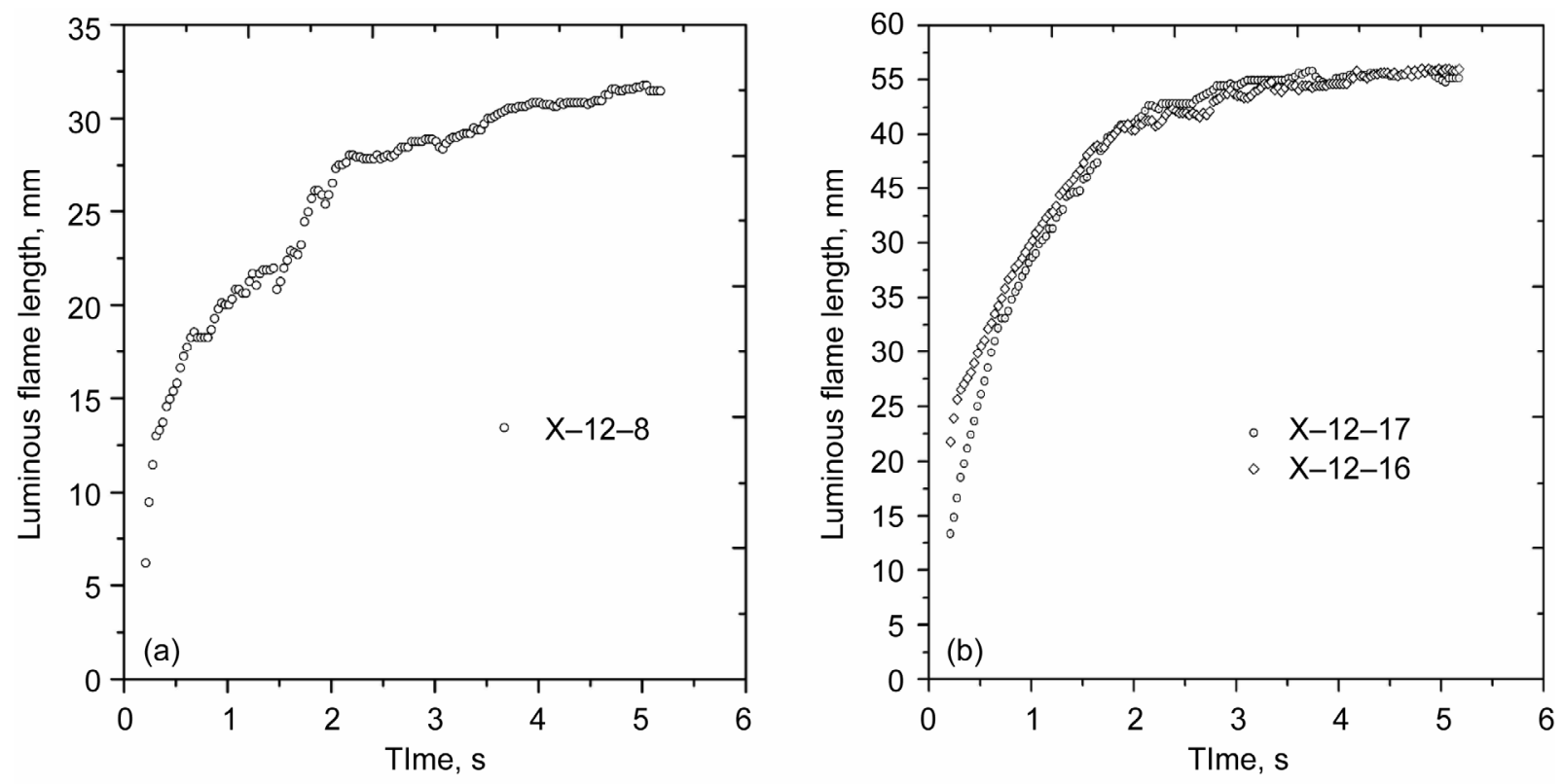

Figure 4.-(a) Luminous flame length time evolution for drop $X-12-18$, ethylene/nitrogen/air flame. (b) Luminous flame length time evolution for drop $\mathrm{X}-12-16$ and $\mathrm{X}-12-17$, ethylene /air flames.

A spectrally broadband radiometer (thermopile) detector (ultraviolet to far infrared) was positioned inside the chamber approximately $20 \mathrm{~cm}$ above the nozzle and to the side of the flame. The radiometer signal, $I_{s}$, is recorded during the drop and is proportional to the total flame radiation, which is roughly the surface area of the flame

$$
I_{s} \approx \frac{\cos ^{2}(\theta / 2)}{r^{2}}
$$

where $r$ is the distance between the radiation source and the detector $(20 \mathrm{~cm})$, and $\theta$ is the angle between the line of sight and the central axis of the detector. For the cases considered in the this study, $\theta$ is small and $\cos ^{2}(\theta / 2) \sim 1$. The results are shown in figure 5 for a laminar methane/air jet flame in drop X-12-6. The initial peak is the result of ignition and excess fuel gas being burned off; however, after $0.75 \mathrm{~s}$ this transient is complete, and the flame begins a steady increase in both flame length and radiative output. After $2 \mathrm{~s}$ the flame radiative output has achieved a near constant value but appears to be increasing slowly. The flame length, shape, and size also remain nearly constant after $2 \mathrm{~s}$. Some technical difficulties prevented a full radiometer signal capture on drop X-12-6 after $4.5 \mathrm{~s}$. Figure 6(a) shows flame radiation data for drops $\mathrm{X}-12-18$ and $\mathrm{X}-12-19$ for a laminar jet diffusion flame diluted 50 percent ethylene and 50 percent nitrogen in air. The initial peak is the result of ignition and excess fuel gas being burned off. In less than $0.5 \mathrm{~s}$ this transient is complete, and the flame begins a steady increase in both flame length and radiative output. Both the flame length and the radiative output of the flame are increasing at the completion of the 5.18 second drop. Very similar results were obtained for an ethylene/air laminar jet diffusion flame shown in figure 6(b) for drops $X-12-16$ and $X-12-17$. Again an ignition transient is observed which disappears in less than $0.5 \mathrm{~s}$, and then the radiative output and the flame length increase throughout the duration of the drop. For the flames considered during the initial phase of the fire, the flame radiation output correlates with the flame size and shape. Throughout longer microgravity duration, other factors begin to affect flame radiation in addition to flame size and surface area or shape. 


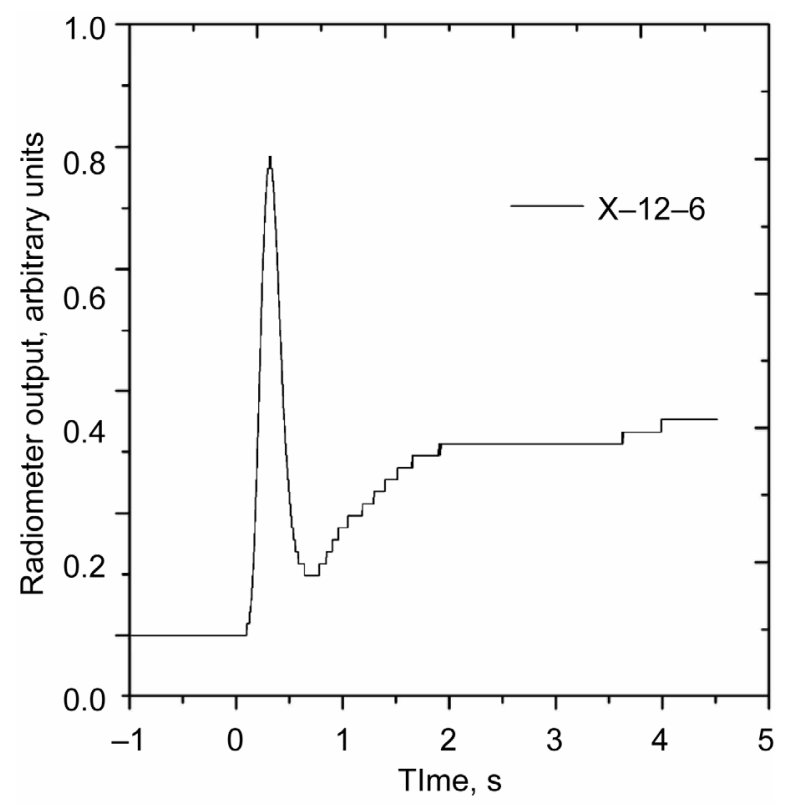

Figure 5.-Radiometer output proportional to total flame broadband spectral and continuum radiation emitted for the flame shown in figure $1(a)$ and $1(b)$, drop X-12-6, methane/air flame.
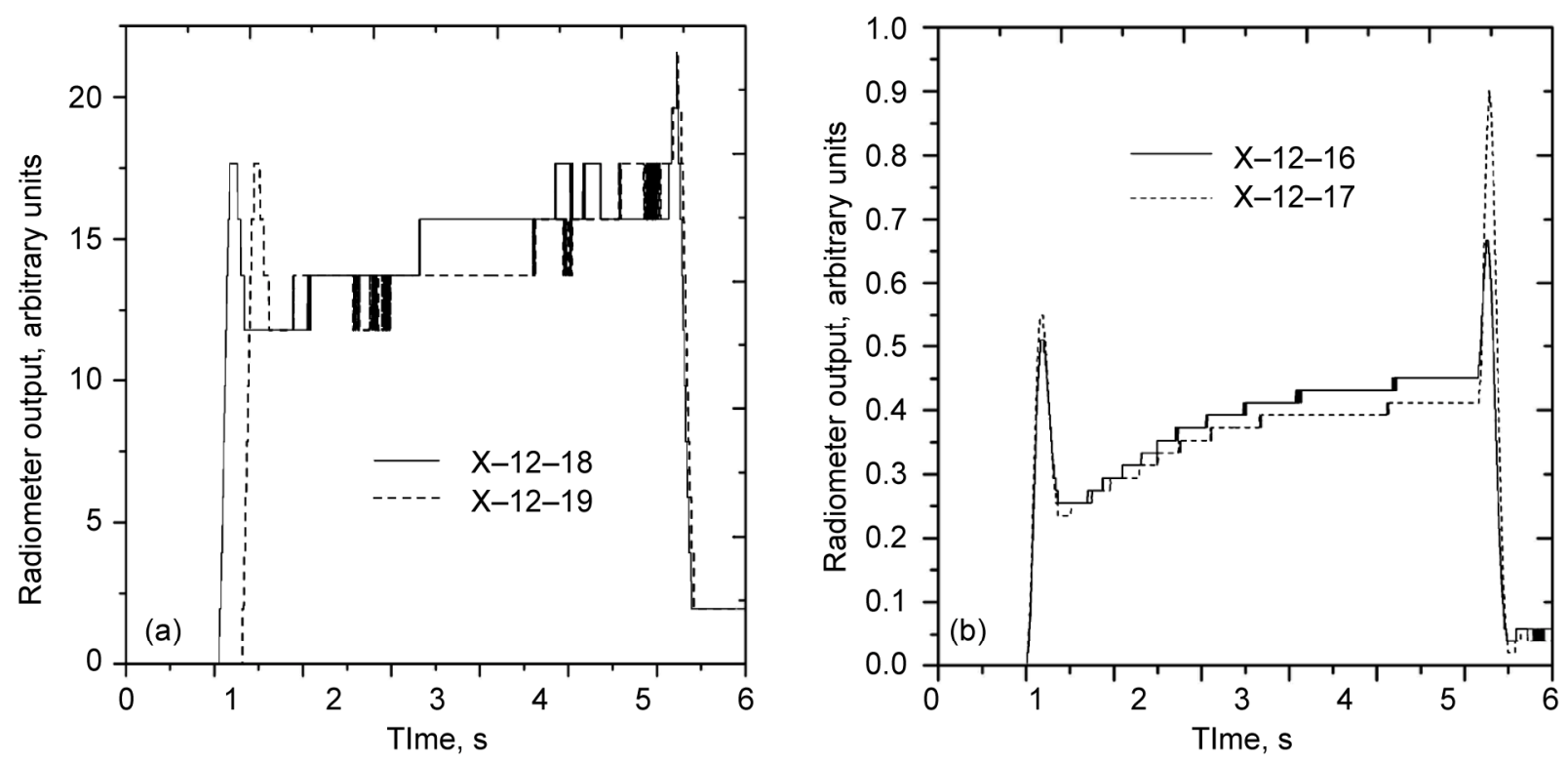

Figure 6.-(a) Radiometer output proportional to total flame broadband spectral and continuum radiation emitted for the flame shown in figure 2(a) and 2(b), drop X-12-18 and X-12-19, 50\% ethylene/nitrogen/air flame.

(b) Radiometer output proportional to total flame broadband spectral and continuum radiation emitted for the flame shown in figure 2(a) and 2(b), drop X-12-16 and X-12-17, ethylene/air flame. 
A scanning mid-IR spectrometer (refs. 10 and 11) was positioned on the drop rig to measure radial profiles of path-integrated intensities at 160 wavelengths from 1.3 to $4.8 \mu \mathrm{m}$ horizontally through the flame in figures 1 to 3 at two heights above the burner exit, at 22.5 and $29 \mathrm{~mm}$ or $x / d=13.6$ and 17.6 , respectively. The spectrometer was fixed outside of the chamber, and the flame was viewed through a sapphire window. The spectrometer is calibrated against a black body radiation source, thus quantitative intensity measurements can be obtained. Radiation in the 1.3 to $3.3 \mu \mathrm{m}$ band has contributions from both $\mathrm{H}_{2} \mathrm{O}$ and $\mathrm{CO}_{2}$. Radiation in the 4.3 to $4.9 \mu \mathrm{m}$ band has contributions only from $\mathrm{CO}_{2}$. Continuum radiation is also present from the radiating soot and is most evident in the 1.3 to $3.3 \mu \mathrm{m}$ band.

\section{Results and Discussion}

As shown in table I, three different fuels were used in order to observe global differences in flame structure such as flame shape, luminous flame length, flame color(s), and total flame emissive power. In addition, local properties have been measured and estimated from path integrated intensity measurements using a mid-IR spectrometer. Local flame properties have been determined using a method know as fan beam emission tomography (FBET) (ref. 10) from the path integrated intensities including soot volume fraction, radiative emissive power, carbon dioxide and water vapor concentrations, and gas temperature. The characteristic residence times shown in table I are calculated based upon the luminous flame length and the average streamwise velocity or the average fuel exit velocity divided by 2 .

$$
\tau_{\text {char }}=\frac{2 L}{u_{0}}
$$

The characteristic residence time for these flames range from $68 \mathrm{~ms}$ to $120 \mathrm{~ms}$ and are significantly larger than in practical, normal gravity fires where $\tau_{\text {char }}$ is typically less than $10 \mathrm{~ms}$.

\subsection{Methane/Air Laminar Diffusion Flames in Microgravity}

In normal gravity a laminar methane/air jet diffusion flame appears mostly "blue" to the human eye with a slight amount of "yellow" continuum radiation from soot particles. In microgravity the flame appears only blue after $2 \mathrm{~s}$ and is dimmer in the visible wavelengths of light than in normal gravity with no visible soot radiation as shown in figure 1.

Figure 7(a) is the "raw" spectrometer data and shows a contour plot of the scanned measured path integrated intensities as a function of wavelength and radial position at $x / d=17.6$. The path integrated intensities shown in figure 7(a) have been averaged over $2.2 \mathrm{~s}$ from $2.8 \mathrm{~s}$ to $5.0 \mathrm{~s}$ during the drop. As seen in figure 5 the flame radiation is nearly steady during this time period of the drop. Figure 7(b) is one slice or one path integrated intensity spectrally resolved from figure 7(a) at a radial position of $r=11.2 \mathrm{~mm}$. The peak at $4.3 \mu \mathrm{m}$ arises from $\mathrm{CO}_{2}$ emission from vibrational and rotational modes of the molecule. The peak at $2.7 \mu \mathrm{m}$ appears from $\mathrm{H}_{2} \mathrm{O}$ and $\mathrm{CO}_{2}$ emissions also from both rotational and vibrational modes of the molecule. It is noteworthy that only discrete gas band radiation is observed in figure 7(b) without the presence of continuum soot radiation.

A deconvolution algorithm and computer code (refs. 10 and 11) were developed which transforms the path integrated intensities into spatially resolved radial profiles of gas temperature, carbon dioxide and water vapor profiles, and soot volume fraction in an axisymmetric, nonhomogeneous flame like those shown in figures 1 to 3. The FBET method makes use of the RADCAL flame radiation database and mathematical model (ref. 12). 

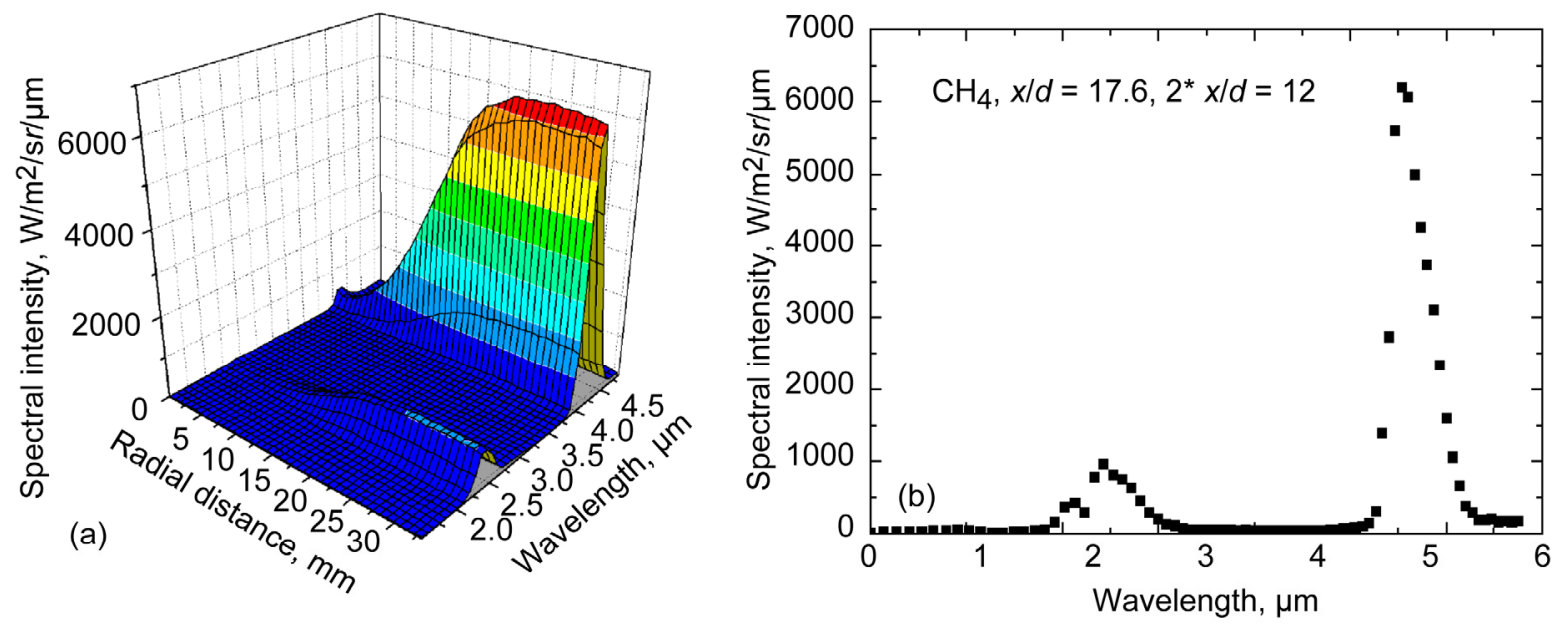

Figure 7.-(a) Contour plot of the measured intensities for drop $X-12-6$ in methane/air flame at $x / d=17.6$. (b) Spectral intensities at $r=11.2 \mathrm{~mm}$ and $x / d=17.6$ for drop $\mathrm{X}-12-6$ the methane/air flame.
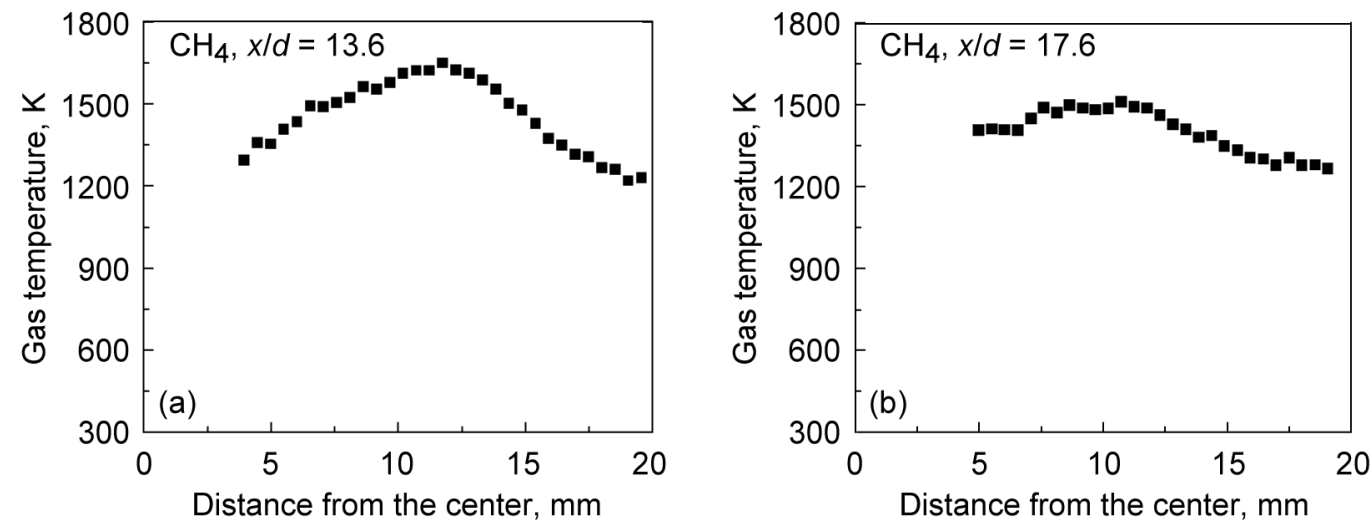

Figure 8.-(a) Temperature profile measured at $x / d=13.6$ for drop $X-12-6$ in methane/air flame.

(b) Temperature profile measured at $x / d=17.6$ for drop $X-12-6$ in methane/air flame.

Figure 8 shows the radial profiles of flame temperature at $\mathrm{x} / d=13.6$ and 17.6 for the methane/air flame shown in figure 1 . The peak flame temperatures decrease from $1675 \mathrm{~K}$ at $x / d=13.6$ to $1500 \mathrm{~K}$ at $x / d=17.6$. For comparison to methane/air laminar diffusion flames in normal gravity, the peak flame temperatures have been measured with FBET and a radiation corrected thermocouple to be $\sim 2100 \mathrm{~K}$, which is significantly hotter than in microgravity but consistent with other measurements and predictions (ref. 10). The microgravity flames are cooler than in normal gravity due to significantly higher fraction of the heat release being lost as radiative heat loss (ref. 9). The principal reason for this phenomenon can be explained by noting that microgravity flames considered here have a long residence time. Fluid particles of fuel exiting the fuel tube reside within the hot flame zone for a relatively long period of time and thereby lose more heat from radiation, cooling the local gas and/or flame temperature than do short residence time flames. Shown in figure 9, at $x / d=13.6$ and 17.6, respectively, are the radial profiles of gas concentration obtained for the methane/air laminar jet diffusion flame in microgravity. At $x / d=13.6$ in figure 9(a), the peak values of $\mathrm{CO}_{2}$ and $\mathrm{H}_{2} \mathrm{O}$ are located at a radial position of approximately $5 \mathrm{~mm}$, which is theoretically the stoichiometric contour and the location of maximum heat release. Here the peak mole fractions are measured to be $\mathrm{X}_{\mathrm{H}_{2} \mathrm{O}}=0.08$ and $\mathrm{X}_{\mathrm{CO}_{2}}=0.165$. Some comparable data exists in the literature to provide an evaluation. In a normal gravity methane/air diffusion flame, Norton et al. (ref. 13) 

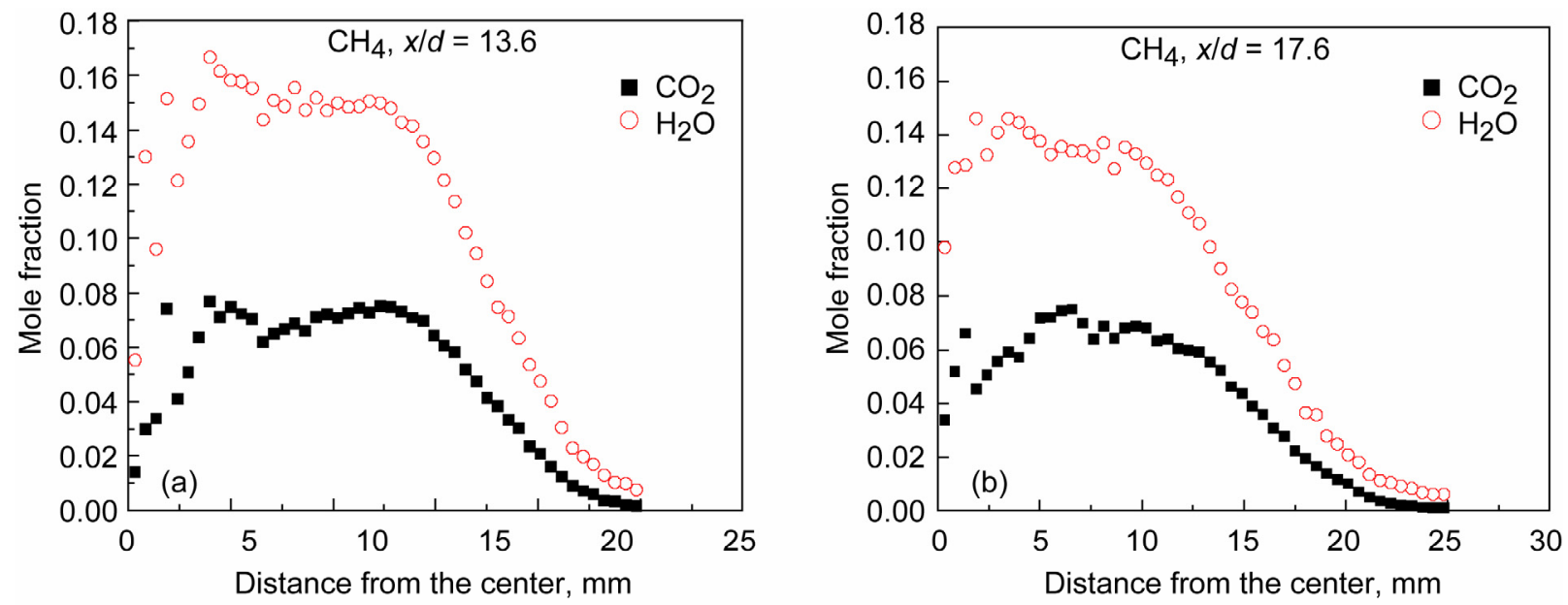

Figure 9.-(a) $\mathrm{CO}_{2}$ and $\mathrm{H}_{2} \mathrm{O}$ profiles measured at $\mathrm{x} / \mathrm{d}=13.6$ for drop $\mathrm{X}-12-6$ in methane/air flame. (b) $\mathrm{CO}_{2}$ and $\mathrm{H}_{2} \mathrm{O}$ profile measured at $x / d=17.6$ for drop $X-12-6$ in methane/air flame.

measured and computed peak values of $\mathrm{CO}_{2}$ and $\mathrm{H}_{2} \mathrm{O}$ mole fractions to be 0.08 and 0.165 with an experimental uncertainty of \pm 20 percent. Sivathanu and Faeth (ref. 14) obtained peak values of $\mathrm{CO}_{2}$ and $\mathrm{H}_{2} \mathrm{O}$ to be 0.075 and 0.172 , respectively, for methane/air diffusion flames in normal gravity, based on generalized state relationships for hydrocarbon flames. Very good agreement is observed, and an important observation can be made that the state relationship for major species is valid during the early combustion phase for methane/air combustion. The adiabatic flame temperature for methane/air combustion is $2140 \mathrm{~K}$, assuming the composition is at the state relationship.

\subsection{Ethylene/Nitrogen/Air Laminar Diffusion Flames in Microgravity}

In normal and microgravity, a laminar 50 percent ethylene and 50 percent nitrogen in air jet diffusion flame appears mostly "yellow" at visible wavelengths due to continuum radiation from soot particles with a slight amount of "blue" radiation outside the soot layer. The stoichiometric contour for this flame lies approximately at the boundary where the luminous yellow radiation ends and the blue radiation appears. The flame is closed-tipped indicating sufficient oxidizer entrainment is present to consume the fuel in an overventilated configuration. In comparison with pure ethylene fuel, the nitrogen dilution has a dramatic effect on reducing the flame length and size.

Figure 10(a) shows the spectrometer data and a contour plot of the scanned measured path integrated intensities as a function of wavelength and radial position at $x / d=17.6$. The path integrated intensities have been averaged over $2.2 \mathrm{~s}$ from $2.8 \mathrm{~s}$ to $5.0 \mathrm{~s}$ during the drop. Figure 4(a) shows the flame radiation is continually increasing during the drop. Figure 10(b) is one line of sight or one path integrated intensity spectrally resolved from figure 10(a) at a radial position of $r=11.2 \mathrm{~mm}$. The peak at $4.3 \mu \mathrm{m}$ arises from $\mathrm{CO}_{2}$ emission, and the peak at $2.7 \mu \mathrm{m}$ appears from $\mathrm{H}_{2} \mathrm{O}$ emission. It is noteworthy that in contrast to the methane/air case shown in figure 7(b), a broadband presence of continuum soot radiation appears in addition to the discrete gas band radiation.

A radial profile of flame temperature at $x / d=17.6$ for the ethylene/nitrogen/air flame is shown in figure 11(a). The peak flame temperature is $1675 \mathrm{~K}$ at $x / d=17.6$ near the centerline of the flame at $r=0.5 \mathrm{~mm}$. The adiabatic flame temperature is $2390 \mathrm{~K}$ for this case indicating significant flame enthalpy losses. 

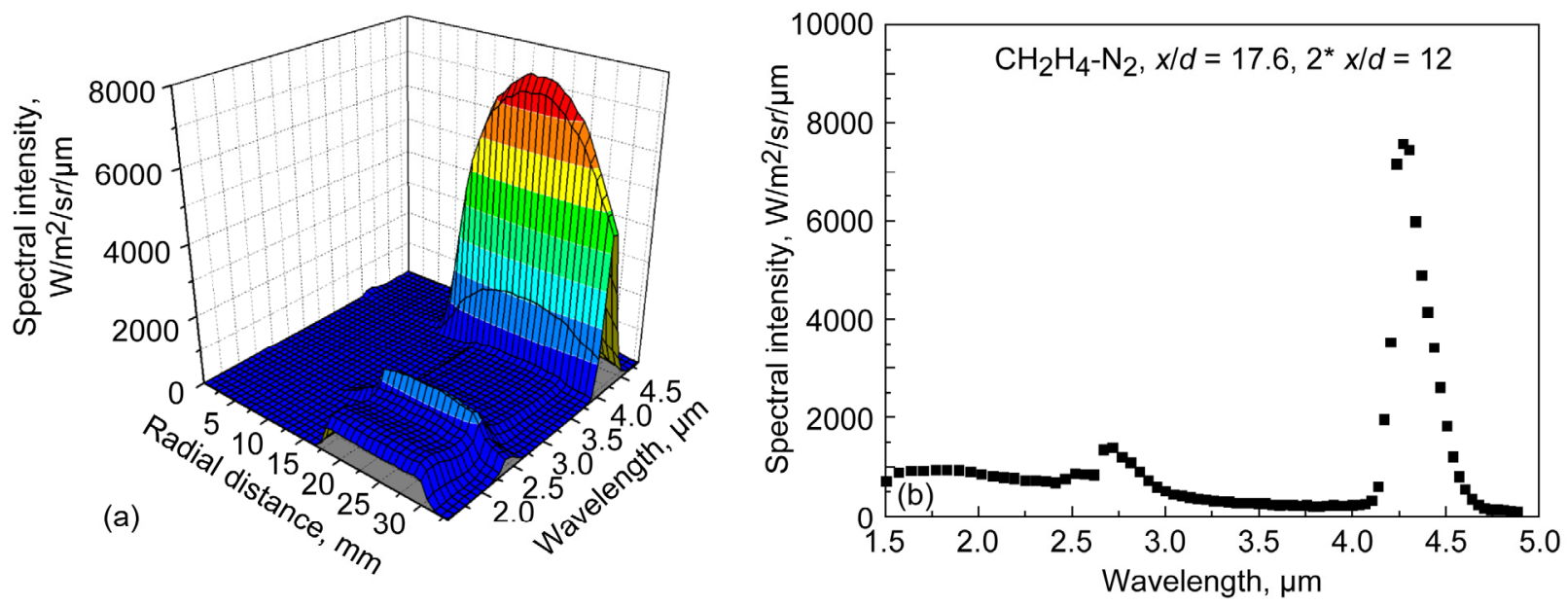

Figure 10.-(a) Contour plot of the measured intensities for drop $X-12-18$ in ethylene/nitrogen/air flame at $x / d=17.6$.

(b) Spectral intensities at $r=11.2 \mathrm{~mm}$ and $x / d=17.6$ for drop $\mathrm{X}-12-18 \mathrm{in}$ an ethylene/nitrogen/air flame.
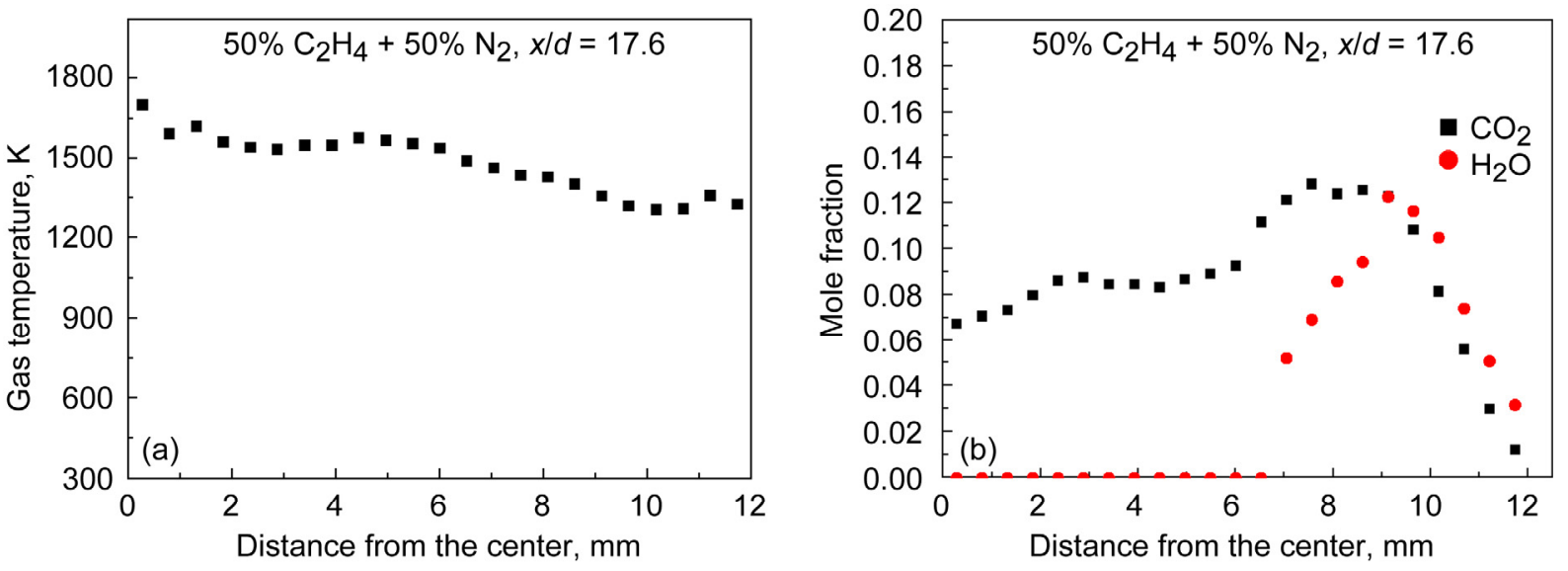

Figure 11.-(a) Temperature profile measured at $x / d=17.6$ for drop $X-12-18$ in an ethylene/nitrogen/air flame.

(b) $\mathrm{CO}_{2}$ and $\mathrm{H}_{2} \mathrm{O}$ profile measured at $x / d=17.6$ for drop $\mathrm{X}-12-6$ in an ethylene/nitrogen/air flame.

\section{TABLE II.-SUMMARY OF STATE RELATIONSHIP MOLE FRACTIONS FOR \\ 50 PERCENT ETHYLENE AND 50 PERCENT NITROGEN/AIR FLAME \\ INITIALLY AT STANDARD TEMPERATURE AND PRESSURE \\ AND AT STOICHIOMETRIC CONDITIONS, $f_{S}=0.05507$}

\begin{tabular}{|c|c|c|c|c|c|c|}
\hline$\phi$ & $\mathrm{X}_{\mathrm{N}_{2}}$ & $\mathrm{X}_{\mathrm{O}_{2}}$ & $\mathrm{X}_{\mathrm{CO}_{2}}$ & $\mathrm{X}_{\mathrm{CO}}$ & $\mathrm{X}_{\mathrm{H}_{2} \mathrm{O}}$ & $\mathrm{X}_{\mathrm{H}_{2}}$ \\
\hline 1.0 & 0.73557 & 0.01990 & 0.09707 & 0.02294 & 0.11529 & 0.00922 \\
\hline
\end{tabular}

The radial profiles for the mole fractions of water vapor and carbon dioxide at $x / d=17.6$ are given in figure 11(b). The peak values for $\mathrm{X}_{\mathrm{H}_{2} \mathrm{O}}$ and $\mathrm{X}_{\mathrm{CO}_{2}}$ are 0.12 and 0.13 , respectively. The state relationship predictions for this flame are given in table II and compared for $\mathrm{X}_{\mathrm{H}_{2} \mathrm{O}}$ and $\mathrm{X}_{\mathrm{CO}_{2}}$ are 0.113 and 0.0955 , respectively, which is within reasonable agreement. Differences in the measured and predicted values can be explained by the fact that the measurements were made near the end of the closed-tip flame where 


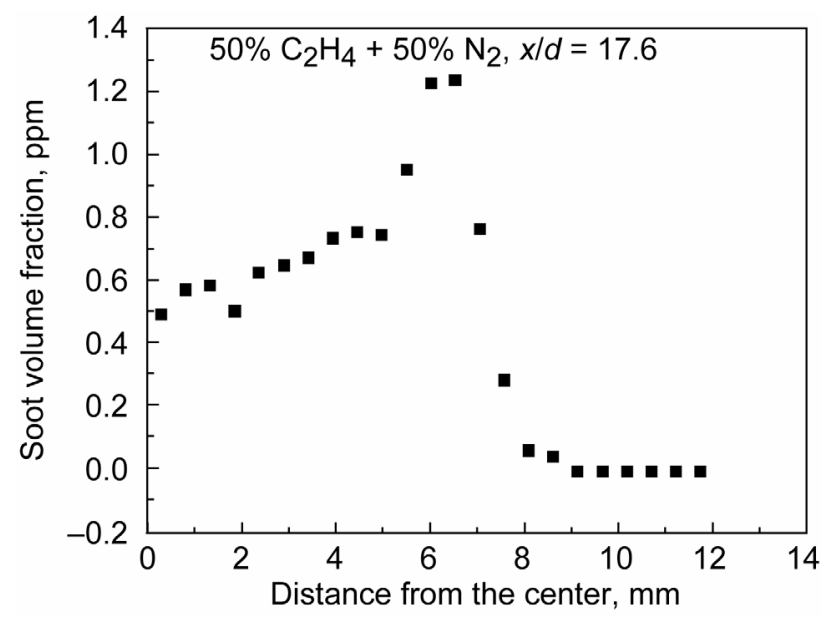

Figure 12.-Soot volume fraction profile for drop $\mathrm{X}-12-18$ obtained in an ethylene/nitrogen/air flame at $x / d=17.6$.

interactions from the closed tip are encountered. The peak values of mole fraction for water vapor and carbon dioxide are located at approximately the same radial location at $r=8 \mathrm{~mm}$ where the stoichiometric mixture fraction is located. Also, it should be noted that the luminous flame zone extends to $r=7 \mathrm{~mm}$ as indicated in table I. The blue glow outside the luminous flame boundary at $r=8 \mathrm{~mm}$ can be seen in figure 2(a), which is the location of the peak carbon dioxide and water vapor production in the flame. Figure 12 presents the soot volume fraction radial profile for drop X-12-18 obtained in an ethylene/nitrogen/air flame at $x / d=17.6$. The stoichiometric composition is positioned at a radius of $8 \mathrm{~mm}$ where the soot production ends. The soot measured from $r=0$ to $6 \mathrm{~mm}$ arises since the measurement is made near the closed tip of the flame (i.e., $x=29 \mathrm{~mm}$ ) and is being transported from upstream locations and produced as well since figure 2(b) clearly shows combustion occurring at the end of the flame tip. The luminous flame ends at $x=32 \mathrm{~mm}$ so this measurement was made within the closedtip end of the flame.

\subsection{Ethylene/Air Laminar Diffusion Flames in Microgravity}

In normal and microgravity, a laminar 50 percent ethylene and 50 percent nitrogen in air jet diffusion flame appears mostly "yellow" at visible wavelengths due to continuum radiation from soot particles with a slight amount of "blue" radiation outside the soot layer. The flame is open tipped indicating insufficient oxidizer is present to consume the fuel in an underventilated configuration.

Figure 13(a) shows a contour plot of the scanned measured path integrated intensities as a function of wavelength and radial position at $x / d=13.6$. These path integrated intensities shown in figure 10 (a) have been averaged over $2.2 \mathrm{~s}$ from $2.8 \mathrm{~s}$ to $5.0 \mathrm{~s}$ during the drop. As seen in figure $6(\mathrm{~b})$, the total flame radiation is nearly steady during this time period of the drop. Figure 13(b) is one line of sight or one path integrated intensity spectrally resolved from figure 10(a) at a radial position of $r=11.2 \mathrm{~mm}$. The peak at $4.3 \mu \mathrm{m}$ arises from $\mathrm{CO}_{2}$ emission, and the peak at $2.7 \mu \mathrm{m}$ appears from $\mathrm{H}_{2} \mathrm{O}$ and $\mathrm{CO}_{2}$ emission. In contrast to the methane/air case shown in figure 7(b) and similar to figure $10(\mathrm{~b})$, a broadband presence of continuum soot radiation appears in addition to the discrete gas band radiation.

A deconvolution algorithm has been developed using an iterative approach to transform the measured path integrated intensities into radial profiles of gas temperature, soot concentration, and both $\mathrm{H}_{2} \mathrm{O}$ and $\mathrm{CO}_{2}$ concentration profiles (refs. 10 and 11). The domain is divided into 128 concentric gas layers, and the flame is understood to be symmetric, which is a reasonable assumption, as seen in figures 1 to 3 . The path integrated intensities have been averaged over $2.2 \mathrm{~s}$ from 2.8 to $5 \mathrm{~s}$. After approximately 8 iterations the gas temperature is obtained and is shown in figure 14 (a) at $x / d=13.6$ and in figure $14(\mathrm{~b})$ at $x / d=17.6$. 

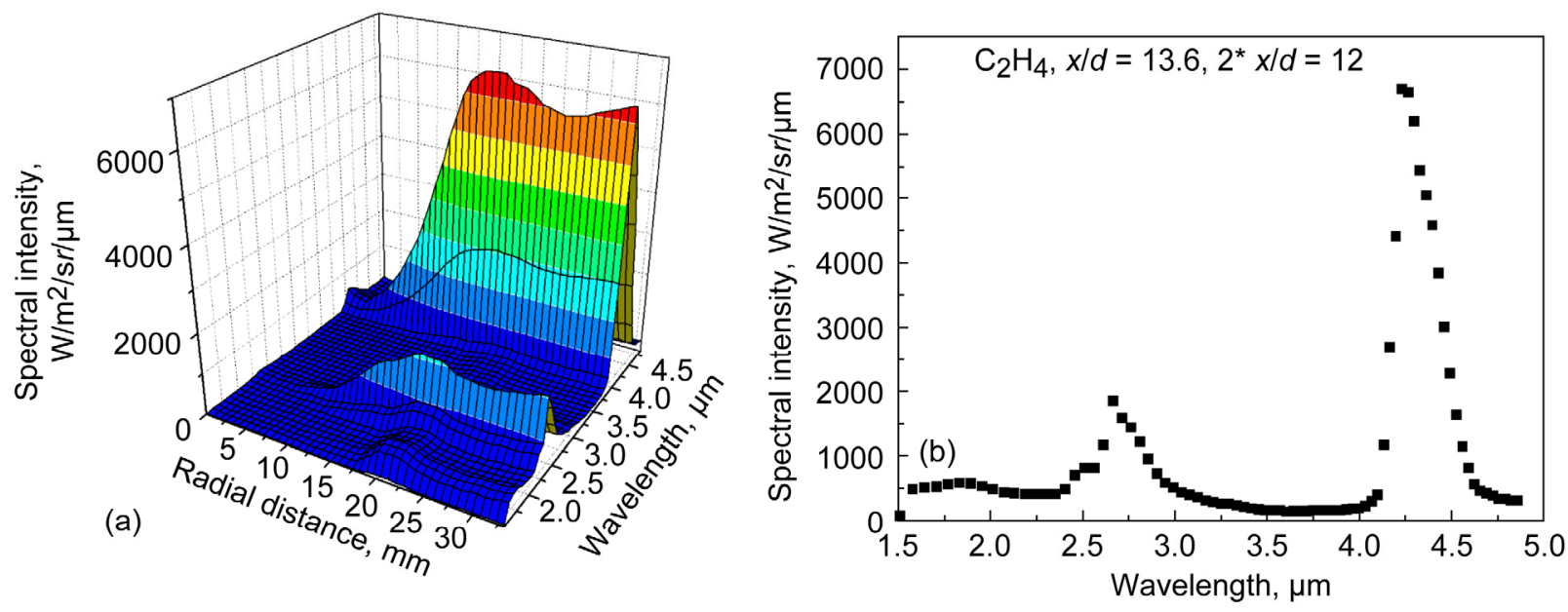

Figure 13.-(a) Contour plot of the measured intensities for drop $X-12-16$ in an ethylene/nitrogen/air flame at $x / d=$ 13.6. (b) Spectral intensities at $r=11.2 \mathrm{~mm}$ and $x / d=13.6$ for drop $X-12-16$ in an ethylene/nitrogen/air flame.
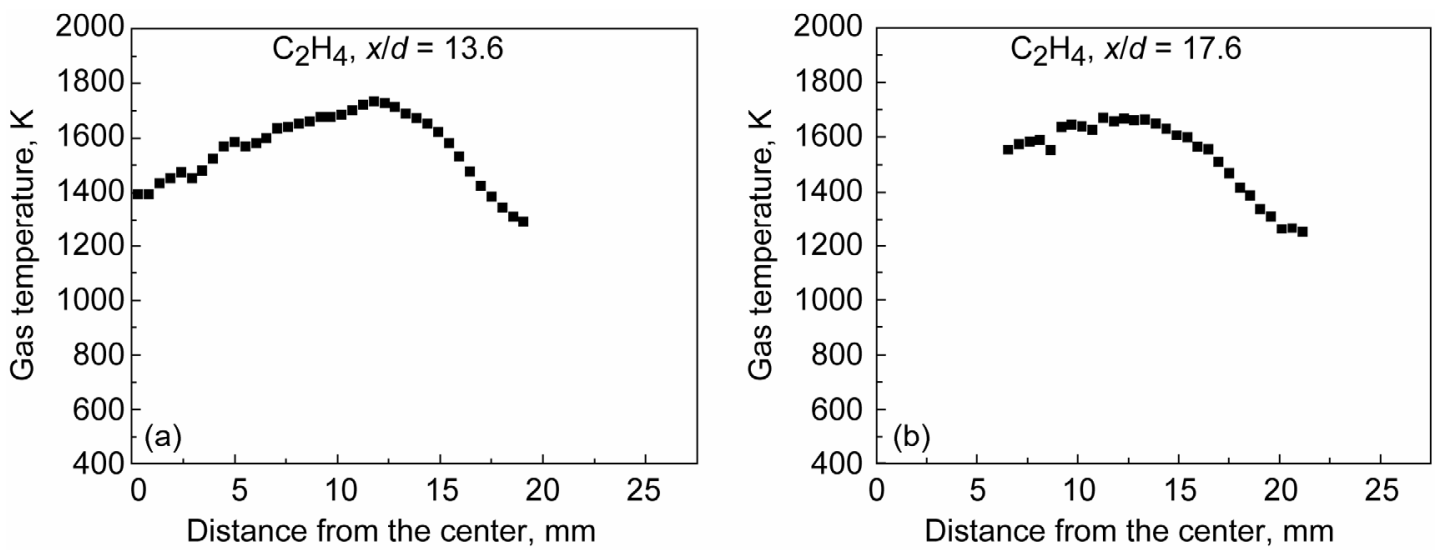

Figure 14.-(a) Temperature profile measured at $x / d=13.6$ for drop $X-12-16$ in an ethylene/air flame. (b) Temperature profile measured at $x / d=17.6$ for drop $X-12-16$ in an ethylene/air flame.

The peak temperature is approximately $1725 \mathrm{~K}$ at a radial position of $12.5 \mathrm{~mm}$ and $x / d=13.6$ and $1675 \mathrm{~K}$ at $x / d=17.6$ and agrees with the results from the LSP experiment (ref. 9). They report a peak temperature of approximately $1850 \mathrm{~K}$ at $x=20 \mathrm{~mm}$ and $1725 \mathrm{~K}$ at $x=30 \mathrm{~mm}$. The luminous flame boundary at $x=22.5 \mathrm{~mm}$ is taken from the color video (fig. 3(a)) to lie at approximately $12.5 \mathrm{~mm}$. For comparison, a normal gravity laminar ethylene/air coflow flame was measured with FBET and thermocouples and is shown in figure 15 . The peak flame temperature is about $2050 \mathrm{~K}$ at $x=15 \mathrm{~mm}$, and the reaction zone is much narrower than in figure 14. The theoretical adiabatic flame temperature for ethylene/air is $2475 \mathrm{~K}$.

A three-channel thermocouple (TC) rake, type R platinum/rhodium alloys, with a wire diameter of $75 \mu \mathrm{m}$ and a bead diameter of approximately $110 \mu \mathrm{m}$ was implemented. The thermocouple rake was positioned at a height of $20 \mathrm{~mm}$ above the burner and at radial locations of $r=5,10$ and $15 \mathrm{~mm}$. Figure 16 shows the uncorrected temperature readings. The flame is disturbed somewhat by the invasive probes and has a luminous flame length of $51 \mathrm{~mm}$ rather than 55 to $56 \mathrm{~mm}$ without the probes. The results show that the flame does broaden as microgravity duration increases and the readings at $r=5$ and $15 \mathrm{~mm}$ are nearly equal after $5 \mathrm{~s}$ in agreement with figure 6(a). In addition the thermocouple reading at $r=10 \mathrm{~mm}$ is higher than at 5 or $15 \mathrm{~mm}$ indicating that peak temperature lies between 5 and $15 \mathrm{~mm}$. 


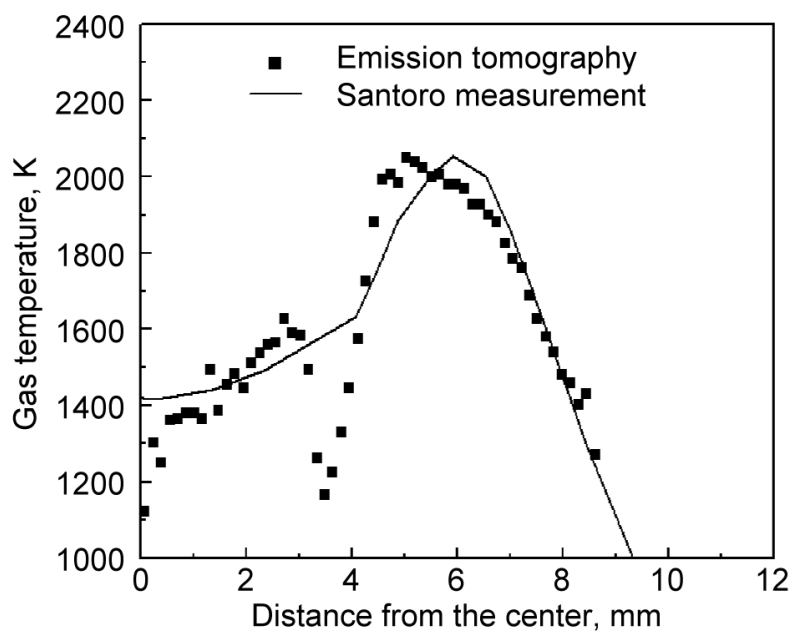

Figure 15.-Thermocouple and emission tomography temperature measurements in a sooting normal gravity laminar coflowing ethylene/air flame (ref. 16), fuel flow rate $3.85 \mathrm{~cm}^{3} / \mathrm{sec}$, air flow rate $713.3 \mathrm{~cm}^{3} / \mathrm{sec}$.

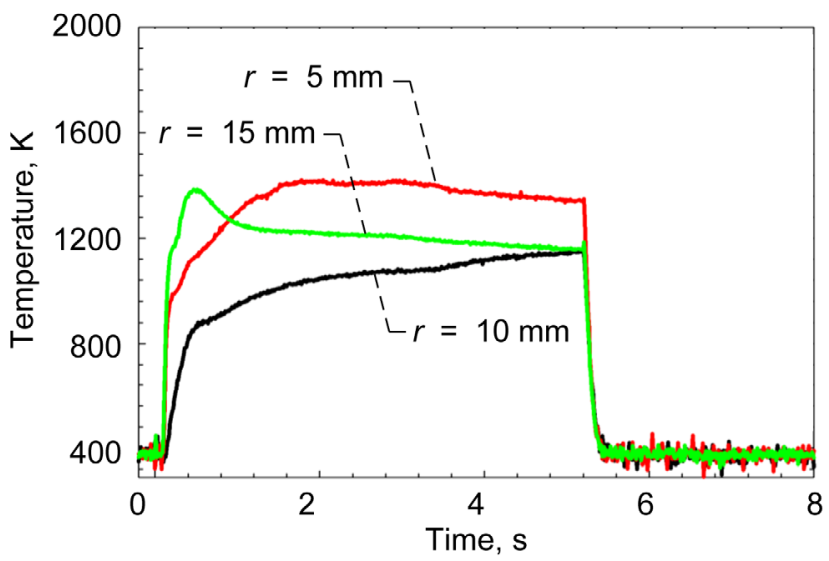

Figure 16.-R-type thermocouple measurements (uncorrected) in ethylene/air flame at $X=20 \mathrm{~mm}(x / d=12)$ and three radial locations: $r=5,10$, and $15 \mathrm{~mm}(x / d=3,6$, and 9), drop $\mathrm{X}-7-5$.

Figure 17 shows radial profiles of both $\mathrm{H}_{2} \mathrm{O}$ and $\mathrm{CO}_{2}$ mole fraction at $x / d=13.6$ and 17.6, respectively. The peak value of mole fraction for $\mathrm{H}_{2} \mathrm{O}$ is approximately 0.10 , and for $\mathrm{CO}_{2}$ the peak value is approximately 0.09 . Both $\mathrm{H}_{2} \mathrm{O}$ and $\mathrm{CO}_{2}$ concentrations at $x=15 \mathrm{~mm}$ were measured in the same normal gravity ethylene/air flame as described in figure 15, and the result is shown in figure 18. Again, the peak value of mole fraction for $\mathrm{H}_{2} \mathrm{O}$ is approximately 0.10 , and for $\mathrm{CO}_{2}$ the peak value is approximately 0.09 - very similar to the microgravity flames. It is also observed that the flame reaction zone is narrower in normal gravity than in nonbuoyant conditions. Generalized state relationship predictions of major gas species concentrations (ref. 14) in an ethylene/air diffusion flame are shown in table III. The measurements are within 20 percent of this value. 

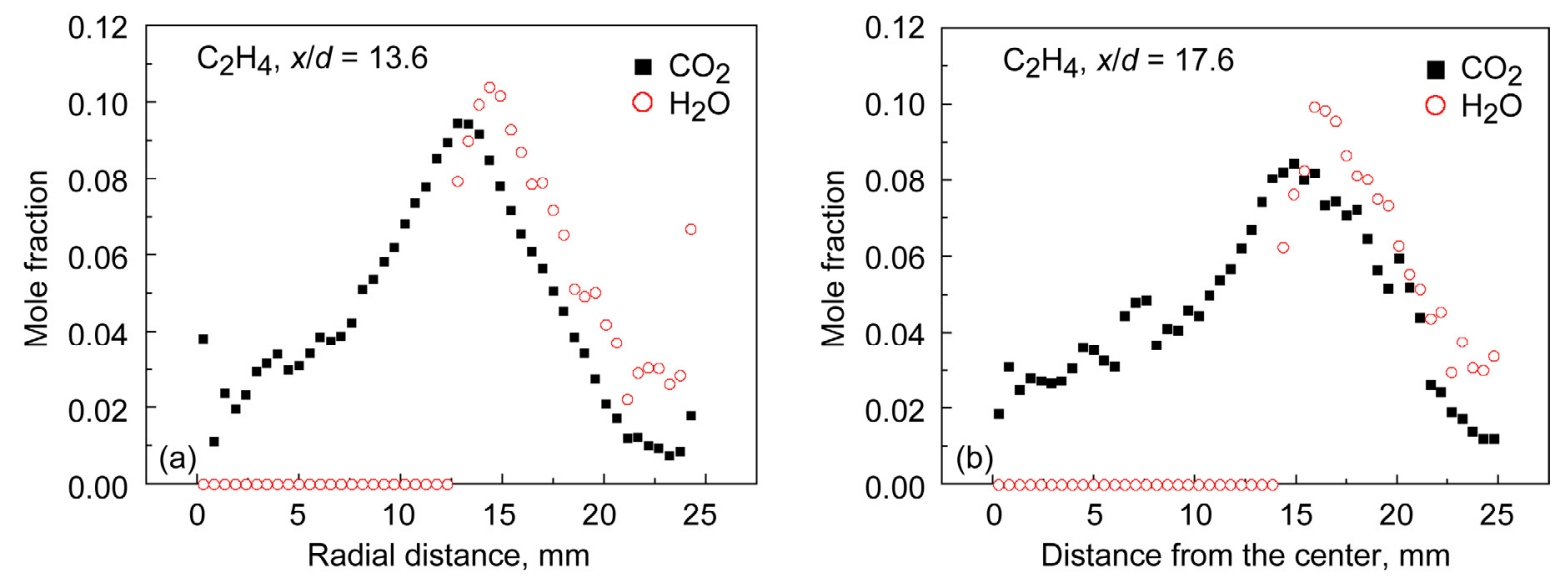

Figure 17.-(a) $\mathrm{CO}_{2}$ and $\mathrm{H}_{2} \mathrm{O}$ profile measured at $x / d=13.6$ for drop $\mathrm{X}-12-16$ in an ethylene/air flame.

(b) $\mathrm{CO}_{2}$ and $\mathrm{H}_{2} \mathrm{O}$ profile measured at $x / d=17.6$ for drop $\mathrm{X}-12-17$ in an ethylene/air flame.

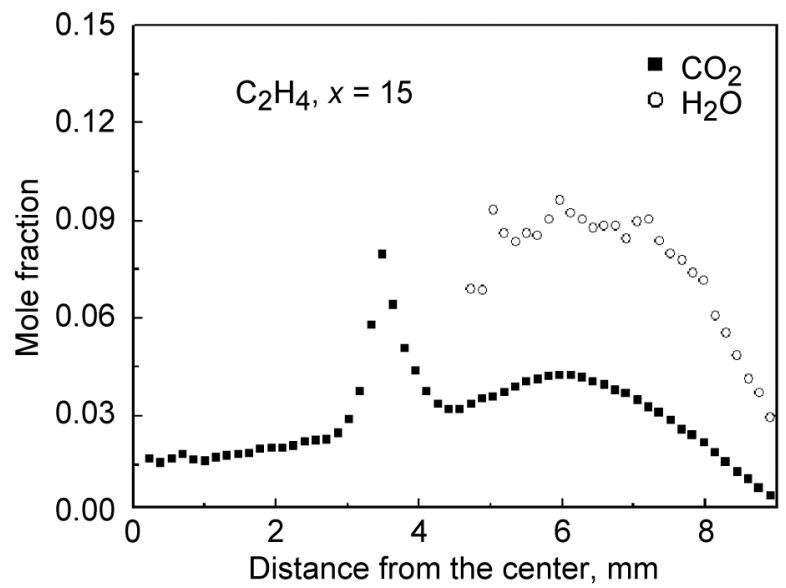

Figure 18. $-\mathrm{H}_{2} \mathrm{O}$ and $\mathrm{CO}_{2}$ concentrations at $x=15 \mathrm{~mm}$ in normal gravity coflow ethylene/air flame, fuel flow rate rate $3.85 \mathrm{~cm}^{3} / \mathrm{sec}$, air flow rate $713.3 \mathrm{~cm}^{3} / \mathrm{sec}$.

TABLE III.-SUMMARY OF STATE RELATIONSHIP MOLE FRACTIONS FOR ETHYLENE/AIR FLAME INITIALLY AT STANDARD TEMPERATURE AND PRESSURE AND AT STOICHIOMETRIC CONDITIONS, $f_{s}=0.06366$ [From ref. 14.]

\begin{tabular}{|c|c|c|c|c|c|c|}
\hline$\phi$ & $\mathrm{X}_{\mathrm{N}_{2}}$ & $\mathrm{X}_{\mathrm{O}_{2}}$ & $\mathrm{X}_{\mathrm{CO}_{2}}$ & $\mathrm{X}_{\mathrm{CO}}$ & $\mathrm{X}_{\mathrm{H}_{2} \mathrm{O}}$ & $\mathrm{X}_{\mathrm{H}_{2}}$ \\
\hline 1.0 & 0.7187 & 0.0212 & 0.1033 & 0.0244 & 0.1227 & 0.0098 \\
\hline
\end{tabular}

The radial profiles of soot volume fraction have been determined from the continuum radiation present in the path integrated intensities and are shown in figure 19 at $x / d=13.6$ and 17.6. The peak value is about $0.8 \mathrm{ppm}$ at 8 to $10 \mathrm{~mm}$ radial position. The soot peak lies on the fuel-rich side of the flame and in the preheat region. The soot is being produced on the fuel rich side of the flame between a fuel equivalence ratio of 3.0 and 1.0 with a peak value at $1.6 \pm 0.3$ according to Gore and Faeth (1986) (ref. 15). This value of $0.8 \mathrm{ppm}$ is much lower that measurements reported previously in microgravity flames. For validation and comparison, the soot volume fraction was measured in a normal gravity sooting ethylene/air flame in a Santoro-type coflow laminar burner (ref. 16) with a fuel flow rate of $3.85 \mathrm{~cm}^{3} / \mathrm{s}$. 

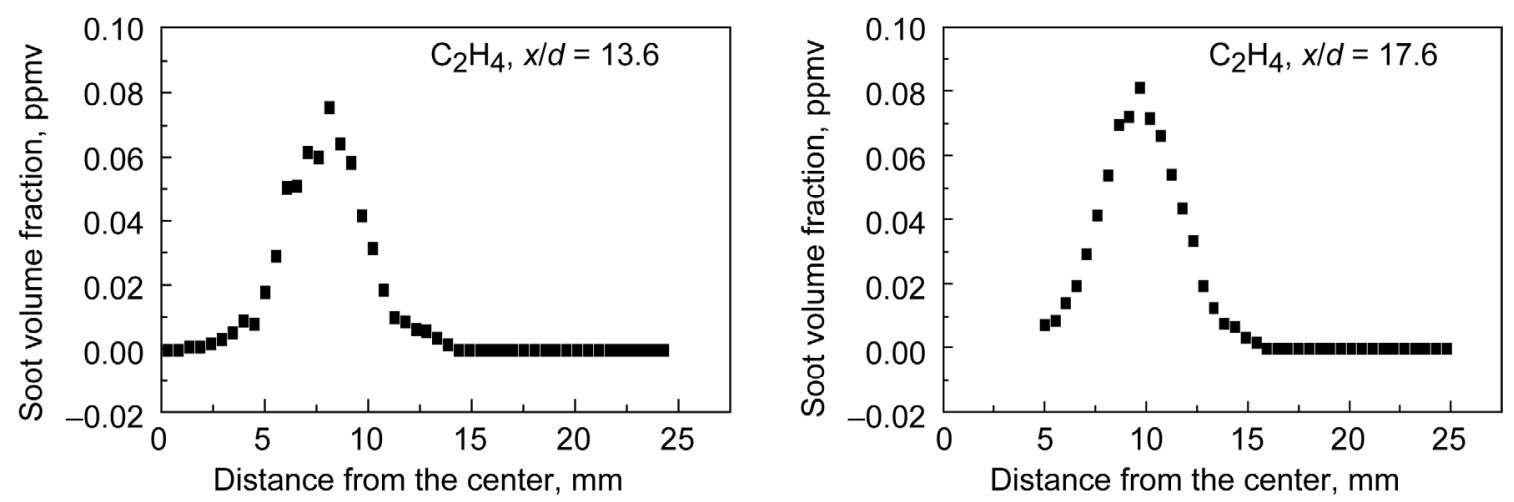

Figure 19.-Soot volume fraction profile obtained in an ethylene flame at $x=22.5 \mathrm{~mm}(\mathrm{X}-12-16)$.

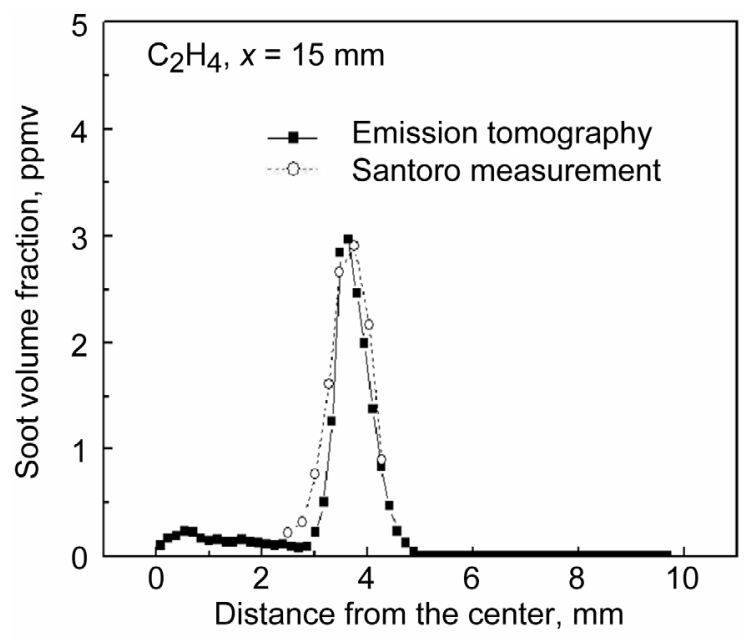

Figure 20.-Laser extinction 17 and emission tomography soot volume measurements in a normal gravity sooting laminar ethylene/air flame at $15 \mathrm{~mm}$ above burner, fuel flow rate $3.85 \mathrm{~cm}^{3} / \mathrm{sec}$.

As shown in figure 20, at $x=15 \mathrm{~mm}$ the peak soot volume fraction was measured to be $3 \mathrm{ppm}$ at a $4 \mathrm{~mm}$ radius. The soot layer is much narrower (i.e., $2 \mathrm{~mm}$ ) as compared with the $5 \mathrm{~s}$ drop test which is $5 \mathrm{~mm}$ thick. Also, soot measurements were made in a long duration microgravity ethylene/air flame or LSP experiment (ref. 9). The peak soot concentrations in the LSP experiment were approximately $5 \mathrm{ppm}$ at $x=20 \mathrm{~mm}$ and 8 to $12 \mathrm{ppm}$ at $x=30 \mathrm{~mm}$ with microgravity duration times of $90 \mathrm{~s}$ and $170 \mathrm{~s}$. The width of the soot layer in the LSP experiment was about $2 \mathrm{~mm}$ at $x=20$ and $30 \mathrm{~mm}$.

\section{Conclusions}

The following conclusions can be obtained from the study

1. A fan beam emission tomography (FBET) system to obtain spectral radiation intensities at several wavelengths and at several view angles from laminar flames was successfully implemented in microgravity. 
2. The laminar microgravity ethylene/air jet flame has a broader reaction zone, has a longer luminous flame length, and is cooler than a similar normal gravity flame. This is in agreement with Bahadori et al. (ref. 7).

3. The soot layer in microgravity after $5 \mathrm{~s}$ duration is $5 \mathrm{~mm}$ which is thicker than in normal gravity (i.e., $2 \mathrm{~mm}$ ). For longer microgravity duration (i.e., $170 \mathrm{~s}$ ) the flame shape changes to be longer and narrower, and the soot layer reduces to about $2 \mathrm{~mm}$ thickness.

4. The peak mole fractions for $\mathrm{H}_{2} \mathrm{O}$ and for $\mathrm{CO}_{2}$ estimated using FBET are in agreement with the values derived from generalized state relationships for methane/air, ethylene/nitrogen/air, and ethylene/air diffusion flames.

\section{References}

1. Freidman, R.: Fire Safety in Extraterrestrial Environments. NASA/TM-1998-207417, 1998.

2. Freidman, R.: Fire Safety in the Low-Gravity Spacecraft Environment. NASA/TM-1999-209285, 1999.

3. Freidman, R.; and Ross, H.D.: Combustion Technology and Fire Safety for Human-Crew Space Missions. Microgravity Combustion: Fire in Free Fall. H.D. Ross, ed., Academic Press, San Diego, CA, 2001, pp. 525-562.

4. Olson, S.L.: Fuel Thickness Effects on Flame Spread and Extinction Limits in Low Gravity as Compared to Normal Gravity. Eastern Section/The Combustion Institute Meeting, 1991.

5. Egorov, S.D. et al.: Fire Safety Experiments on "Mir" Orbital Station. NASA CP-10174, 1995, pp. 195-199.

6. Ivanov, A.V. et al.: Experimental Verification of Material Flammability in Space. NASA/CR-1999$209405,1999$.

7. Bahadori, M.Y. et al.: Effects of Buoyancy on Laminar, Transitional, and Turbulent Gas Jet Diffusion Flames. Modern Developments in Energy, Combustion and Spectroscopy, ch. 4, F.A. Williams et al., eds., Pergamon Press, 1993, pp. 49-66.

8. Ruff, G.A.; Urban, D.L.; and King, M.K.: Fire Prevention, Detection, and Suppression Research Supporting Manned Space Exploration: One Year Later. AIAA-2006-0347, 2006.

9. Urban, D.L. et al.: Structure and Soot Properties of Nonbuoyant Ethylene/Air Laminar Jet Diffusion Flames. AIAA J., vol. 36, no. 8, 1998, pp. 1346-1360.

10. Lim, J.; Sivathanu, Y.; and Feikema, D.A.: Fan Bean Emission Tomography. AIAA-2006-0437, Aerospace Sciences Meeting, Reno, NV, 2006.

11. Lim, J.; Sivathanu, Y.; and Gore, J.: Estimating Scalars From Spectral Radiation Measurements in a Homogeneous Gas Layer. Comb. Flame, vol. 137, 2004, pp. 222-229.

12. Grosshandler, W.L.: Radiative Heat Transfer in Nonhomogeneous Gases: A Simplified Approach. Int. J. Heat Mass Transfer, vol. 23, 1980, pp. 1447-1459.

13. Norton, T.S. et al.: Comparison of Experimental and Computer Species Concentrations and Temperature Profiles in Laminar Two-Dimensional Methane/Air Diffusion Flames. Combust. Sci. Technol., vol. 53, 1993, pp. 1-34.

14. Sivathanu, Y.; and Faeth, G.M.: Generalized State Relationships for Scalar Properties in Nonpremixed Hydrocarbon/Air Flames. Comb. Flame, vol. 82, 1990, pp. 211-230.

15. Gore, J.; and Faeth, G.M.: Structure and Spectral Radiation Properties of Turbulent Ethylene/Air Diffusion Flames. Twenty-First International Symposium on Combustion, 1986, pp. 1521-1531.

16. Santoro, R.J. et al.: The Transport and Growth of Soot Particles in Laminar Diffusion Flames. Combust. Sci. Technol, vol. 53, 1987, pp. 89-115.

17. Santoro, R.J.; Semerjian, H.G.; and Dobbins, R.A.: Soot Particle Measurements in Diffusion Flames. Comb. Flame, vol. 51, 1983, pp. 203-218. 


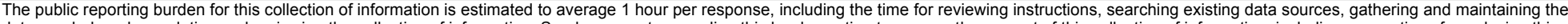

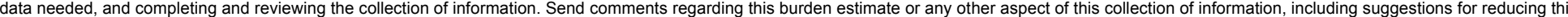

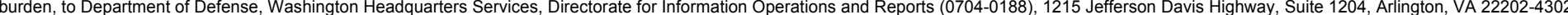

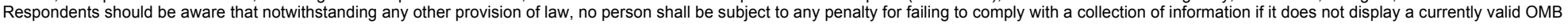
control number.

PLEASE DO NOT RETURN YOUR FORM TO THE ABOVE ADDRESS.

\section{REPORT DATE (DD-MM-YYYY) \\ 2. REPORT TYPE \\ 3. DATES COVERED (From - To)}

01-06-2007

\section{TITLE AND SUBTITLE}

Flame Radiation, Structure, and Scalar Properties in Microgravity Laminar Fires

\section{5a. CONTRACT NUMBER}

NAS3-01085

5b. GRANT NUMBER

5c. PROGRAM ELEMENT NUMBER

5d. PROJECT NUMBER

6. AUTHOR(S)

Feikema, Douglas; Lim, Jongmook; Sivathanu, Yudaya 5e. TASK NUMBER

5f. WORK UNIT NUMBER

WBS 732759.03.01.02.21

\section{PERFORMING ORGANIZATION \\ REPORT NUMBER}

E-15833

National Aeronautics and Space Administration

John H. Glenn Research Center at Lewis Field

Cleveland, Ohio 44135-3191

\section{SPONSORING/MONITORING AGENCY NAME(S) AND ADDRESS(ES)}

National Aeronautics and Space Administration

Washington, DC 20546-0001

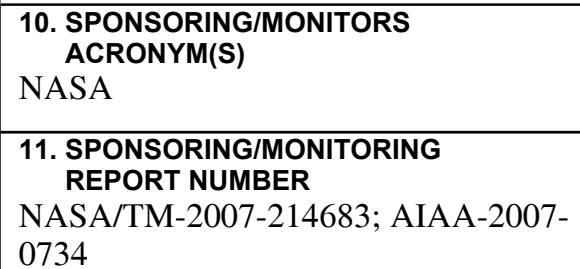

\section{DISTRIBUTION/AVAILABILITY STATEMENT}

Unclassified-Unlimited

Subject Categories: 31, 34, 25, 74, and 35

Available electronically at http://gltrs.grc.nasa.gov

This publication is available from the NASA Center for AeroSpace Information, 301-621-0390

\section{SUPPLEMENTARY NOTES}

\section{ABSTRACT}

Results from microgravity combustion experiments conducted in the Zero Gravity Research Facility (ZGF) 5.18 second drop facility are reported. The results quantify flame radiation, structure, and scalar properties during the early phase of a microgravity fire. Emission midinfrared spectroscopy measurements have been completed to quantitatively determine the flame temperature, water and carbon dioxide vapor concentrations, radiative emissive power, and soot concentrations in microgravity laminar methane/air, ethylene/nitrogen/air and ethylene/air jet flames. The measured peak mole fractions for water vapor and carbon dioxide are found to be in agreement with state relationship predictions for hydrocarbon/air combustion. The ethylene/air laminar flame conditions are similar to previously reported results including those from the flight project, Laminar Soot Processes (LSP). Soot concentrations and gas temperatures are in reasonable agreement with similar results available in the literature. However, soot concentrations and flame structure dramatically change in longduration microgravity laminar diffusion flames as demonstrated in this report.

\section{SUBJECT TERMS}

Mid-IR spectroscopy; Flames; Combustion; Concentration and temperature measurements; Optical instrumentation

\begin{tabular}{|c|c|c|c|c|}
\hline 16. SECURI & ASSIFICATION & & 17. LIMITATION OF & 18. NUMBER \\
\hline $\begin{array}{l}\text { a. REPORT } \\
\text { U }\end{array}$ & $\begin{array}{l}\text { b. ABSTRACT } \\
\text { U }\end{array}$ & $\begin{array}{l}\text { c. THIS } \\
\text { PAGE } \\
\text { U }\end{array}$ & & $\begin{array}{c}\text { PAGES } \\
22\end{array}$ \\
\hline
\end{tabular}



